\title{
ATRIBUCIÓN CAUSAL A TRAUMAS CRANEOFACIALES EN MUESTRAS DEL NORTE DE PATAGONIA (REPÚBLICA ARGENTINA): UNA PERSPECTIVA EXPERIMENTAL
}

\author{
FLORENCIA GORDÓN*
}

\begin{abstract}
RESUMEN
En el marco de la evaluación de una hipótesis que relaciona cambios ecológicos acontecidos durante la Anomalía Climática Medieval (1.150-600 años calendáricos AP) con aumentos en los niveles de violencia en el noreste de Patagonia, ha sido detectada una elevada frecuencia de un tipo particular de trauma en la muestra de individuos más tardía analizada. En este contexto, se propone el desarrollo de dos líneas de evidencia. Por un lado, un relevamiento bibliográfico de la ergología regional. Por otro, y con mayor énfasis, la aplicación de un programa experimental que permita plantear posibles relaciones entre efectores y trazas. La primera línea dio cuenta del aspecto generalizado y multipropósito que caracteriza al conjunto artefactual de los grupos que habitaron el área previo a la llegada de las poblaciones europeas. Sin embargo, la presencia de armas blancas desde, por lo menos mediados del siglo XVII, podría explicar la elevada frecuencia de estas lesiones que caracterizan a la muestra más tardía. En este sentido, los primeros resultados de naturaleza macroscópica obtenidos del estudio experimental, para el cual fueron utilizados sables y cabezas de cerdo como proxies, apuntan en esta dirección. La recurrencia de estas lesiones en individuos procedentes de contextos tardíos, cuya última aparición se sitúa hacia 350 años AP, estaría registrando momentos tempranos del período colonial, aunque posteriores a la Anomalía Climática Medieval.
\end{abstract}

PALABRAS CLAVE: análisis experimental, ergología regional, violencia interpersonal, NE de Patagonia, Holoceno tardío.

\section{CAUSAL ATTRIBUTION TO CRANEOFACIAL TRAUMA FROM NORTHERN PATAGONIAN SAMPLES (REPÚBLICA ARGENTINA): AN EXPERIMENTAL PERSPECTIVE}

\begin{abstract}
In the context of assessment of the hypothesis which relates ecological changes during Medieval Climatic Anomaly (1.150-600 calendar years BP) with increasing levels of violence in Northeastern Patagonia, a particular type of trauma in the latest sample was detected. In this context, two lines of evidence
\end{abstract}


FLORENCIA GORDÓN

are proposed: on the one hand, a bibliographic survey of the regional technology; on the other, more emphatically, the application of an experimental program which allows to make possible links between effectors and traces. The first line of evidence sheds light on the generalized and multipurpose characteristics of the toolkit of the local groups before the European population arrived. However, the presence of metallic blades since, at least the middle of XVII century, could explain the high frequency of linear depressions which characterizes latest sample. In this sense, the first results of the experimental survey, of macroscopic nature, for which long blades and heads of pigs were used as proxies, are concurrent. The recurrence of these injuries in individuals from late contexts, which latest dates are of 350 years BP, would be recording early moments of the colonial period, although later than Medieval Climatic Anomaly.

KEY WORDS: experimental survey, regional ergology, interpersonal violence, northeastern Patagonia, late Holocene.

\section{INTRODUCCIÓN}

El presente trabajo se inserta dentro de un proyecto de investigación más amplio cuyo objetivo es analizar la distribución espacial y temporal de señales de violencia interpersonal durante el Holoceno tardío en el noreste de la Patagonia, República Argentina. Para tal fin se están analizando muestras de cráneos humanos procedentes de los valles inferiores de los ríos Colorado, Negro y Chubut y del litoral atlántico bonaerense (Isla Gama y Bahía San Blas) correspondientes a los últimos 3.000 años ${ }^{14} \mathrm{C}$ AP.

Para llevar a cabo el mencionado proyecto se propuso el desarrollo de investigaciones referidas a cuatro líneas de evidencia. Las mismas son: 1) registro de frecuencia, tipo y distribución por sexo y edad de lesiones óseas atribuibles a situaciones de violencia; 2) tipos de artefactos potencialmente utilizables para ocasionar lesiones traumáticas presentes en contextos arqueológicos regionales; 3) análisis comparativo de marcas registradas en restos óseos arqueológicos y análogos experimentales; 4) información etnográfica y etnohistórica. Hasta el momento se cuenta con mayor cantidad y calidad de información en lo concerniente a la primera línea de evidencia (Barrientos y Gordón 2004; Gordón y Ghidini 2006; Gordón 2008).

En el caso de la submuestra más tardía (ca. 1.300-350 años ${ }^{14} \mathrm{C}$ AP) (Barrientos 2001; Barrientos et al. 2005; Bernal et al. 2008; Berón y Baffi 2003; Gómez Otero y Dahinten 1997/1998), el registro de una elevada frecuencia relativa de lesiones traumáticas correspondientes a la categoría "depresiones lineales" y la presencia de "cortes tangenciales" (Barrientos y Gordón 2004), condujo a la necesidad de formular una hipótesis causal para intentar dar cuenta de las mismas. A este respecto, cabe señalar que algunos autores (Lambert 2002; Ubelaker 1991), han propuesto que las lesiones óseas reflejan, aproximadamente, el tamaño y la forma de los instrumentos u objetos que las generaron. Siguiendo este argumento, puede decirse que las depresiones lineales poseen una serie de rasgos morfológicos que son comunes y consistentes entre sí que permiten inferir que fueron producidas por alguna clase de artefacto relativamente estandarizada, probablemente de hoja y de filo recto y agudo. Dado que se cuenta con información etnohistórica que menciona la presencia de armas blancas en la región durante los primeros momentos de contacto hispano-indígena (Bechis 1998; Villar y Jiménez 2001 , entre otros), es probable que estas lesiones correspondan, en general, a la acción de este tipo de armas. Las armas blancas pueden ser definidas como armas ofensivas de hoja metálica. Las mismas pueden dividirse en armas blancas de puño (cortas: estilete, daga, puñal, cuchillo, machete, etc. y largas: florete, estoque, espada, sable); de asta (cortas: hacha, pilum, jabalina y largas: lanza, alabarda, corsesca) y de enastar, como la bayoneta (Bassús 2008 MS).

Es significativo señalar que parte de los individuos que exhiben tales lesiones muestran evidencias de una modalidad de entierro secundario que estuvo presente en el área hasta momentos históricos (Barrientos 1997, 2001; Martínez 2004; Martínez et al. 2006). Esta situación abre la interesante perspectiva de estar en presencia del registro de eventos correspondientes a las primeras etapas del contacto entre la sociedad colonial y las sociedades aborígenes del 
noreste de Patagonia, lo cual constituye un tipo de evidencia inusual en la región.

Con el objeto de evaluar la hipótesis causal formulada para el tipo de lesiones identificadas como "depresiones lineales" y "cortes tangenciales", se encuentra actualmente en desarrollo un programa experimental orientado a replicar tales modificaciones óseas mediante la acción de diversas armas blancas usadas en Norpatagonia en diferentes momentos de contacto hispano-indígena sobre cabezas de cerdos recién faenados, como proxies de cráneos humanos. Se espera de este modo obtener una serie de criterios diagnósticos, mediante la observación directa de las interacciones entre efectores y trazas (sensu Gifford-González 1991), de naturaleza macroscópica y microscópica que puedan ser utilizados para su comparación con las lesiones registradas en los cráneos humanos analizados. De este modo se busca reducir el nivel de ambigüedad presente actualmente en la interpretación de tales traumas.

El objetivo principal de este trabajo es plantear relaciones entre efectores y trazas. Es decir, hipotetizar posibles atribuciones causales a los diversos tipos de traumas, específicamente a las mencionadas lesiones recurrentes en el grupo de individuos más tardío: depresiones lineales y cortes tangenciales. Para alcanzar tal objetivo se presentarán los resultados obtenidos de dos estrategias de acercamiento. Por un lado, aquellos generados a partir de una revisión bibliográfica que de cuenta de las características de la ergología general de sociedades de pequeña escala y de la ergología regional. Por otro lado, y con particular énfasis, se expondrá el diseño experimental puesto en práctica y se presentarán los primeros resultados obtenidos, específicamente aquellos referidos a la morfología macroscópica de las lesiones traumáticas inducidas experimentalmente y su comparación con los casos arqueológicos observados.

Como una forma de retomar y enmarcar el objetivo de este trabajo, se presentarán brevemente los resultados obtenidos hasta el momento en cuanto al patrón general de violencia inferido para el noreste de Patagonia durante el Holoceno a partir del análisis de muestras óseas de individuos adultos (Buikstra y Ubelaker 1994) en concordancia con la primera línea de evidencia propuesta (Barrientos y Gordón 2004; Gordón y Ghidini 2006; Gordón 2008).

Finalmente, dado que la presencia de armas blancas en el área de estudio se asocia al contacto (ya sea directo o indirecto) entre la población aborigen y la colonial, un aporte del trabajo experimental tendrá un sentido cronológico. Es decir, que mediante la caracterización de los traumas generados por armas blancas podría inferirse una antigüedad relativa de aquellos individuos que exhiben lesiones análogas, ubicada en los primeros momentos de contacto hispano-indígena.

\section{VIOLENCIA INTERPERSONAL EN SOCIEDADES DE PEQUEÑA ESCALA: EL NORESTE DE PATAGONIA DURANTE EL HOLOCENO TARDÍO}

En general, y como ya fuera expuesto en trabajos anteriores (Gordón 2007; Gordón y Ghidini 2006), las denominadas sociedades de pequeña escala practican un tipo de violencia que es relativamente uniforme a través del tiempo y del espacio. Al mismo se lo denomina comúnmente "violencia interpersonal" (Gat 1999, 2000) para diferenciarla de las tradicionales definiciones de "guerra" que generalmente denotan una situación de agresión violenta, armada y organizada entre miembros de grupos sociales políticamente autónomos (Smith 2003).

Los grupos humanos que habitaron el noreste de Patagonia a la llegada de los primeros europeos presentaban características organizacionales que los ubican entre aquellas sociedades denominadas de pequeña escala (Silberbauer 1993): caracterizadas por una demografía regional relativamente baja, niveles de movilidad residencial variables y una economía basada en la caza, en la recolección y, probablemente, en la pesca (Eugenio y Aldazabal 2004; Favier-Dubois et. al. 2006; Gómez Otero 2006; Gómez Otero et. al. 1999; Martínez et. al. 2009; Vignati 1931).

Para el noreste de la Patagonia y en lo que respecta al período correspondiente a la denominada Anomalía Climática Medieval (ca. 1.150 - 600 años calendáricos AP; Stine 1994, 2000), se ha propuesto la existencia de probables aumentos locales en la densidad demográfica de las poblaciones del área, particularmente en los cursos inferiores de los grandes ríos y en el litoral atlántico (Barrientos y Perez 2004; Gómez Otero 2006). Esto podría, a su vez, haber creado las condiciones para la ocurrencia de aumentos correlacionados en los niveles de violencia 
interpersonal (para una discusión de la literatura relevante acerca de este tópico, ver Barrientos y Gordón 2004). Para poner a prueba esta hipótesis, se inició el estudio de la distribución temporal y espacial de las lesiones traumáticas atribuibles a violencia interpersonal en muestras de restos óseos humanos de la región.

El patrón general de violencia interpersonal inferido para el noreste de Patagonia se hizo sobre la base de un total de 377 unidades anatómicas correspondientes a cráneos. La muestra analizada forma parte de las colecciones de restos óseos humanos que se encuentran depositadas en la División Antropología del Museo de La Plata (Facultad de Ciencias Naturales y Museo, Universidad Nacional de La Plata). Las zonas consideradas para este trabajo corresponden al valle inferior del río Negro (Colección Moreno, 1874) y al valle inferior del río Chubut (Colecciones Moreno 1876-77, Cremonessi, sin fecha exacta y Pozzi 1893) (Fig.1).

La muestra fue subdividida según diversos criterios. Por un lado, se tuvo en cuenta la procedencia: valles inferiores de los ríos Negro $(n=221)$ y Chubut $(n=156)$. También se subdividió según el sexo: masculinos $(n=178)$, femeninos $(n=159)$ $e$ indeterminados $(n=40)$ (Buikstra y Ubelaker 1994; Pérez 2006). Finalmente, un tercer criterio de agrupamiento fue el temporal, basado en la presencia y modalidad de deformación artificial del cráneo (Dembo e Imbelloni 1938; Imbelloni 1924-25; Pérez 2006). En el área de estudio, este rasgo es un adecuado indicador temporal, ya que la distribución cronológica atribuida a cada uno de los diferentes tipos de deformación sobre la base de fechados radiocarbónicos, presenta una escasa superposición, lo cual permite seriar a las muestras con un alto grado de confianza. Este criterio generó los siguientes grupos: circulares y/o pseudocircular (C): esta modalidad se registró en el valle del río Negro ( $n=36)$. La misma cuenta con fechados radiocarbónicos en el sudeste de la región pampeana, Pampa Seca y valle inferior del río Negro que la ubican entre 8.000 y 2.600 años AP (Barrientos 2001; Bernal et al. 2008; Berón y Baffi 2003). Un grupo de individuos presentó deformación tabular erecta planofrontal (TEPF) $(n=38)$. La misma se registró tanto en el valle del río Negro como en el del Chubut, y presenta fechados que oscilan entre 2.600 y 1.300 años AP (Bernal et al. 2008; Gómez

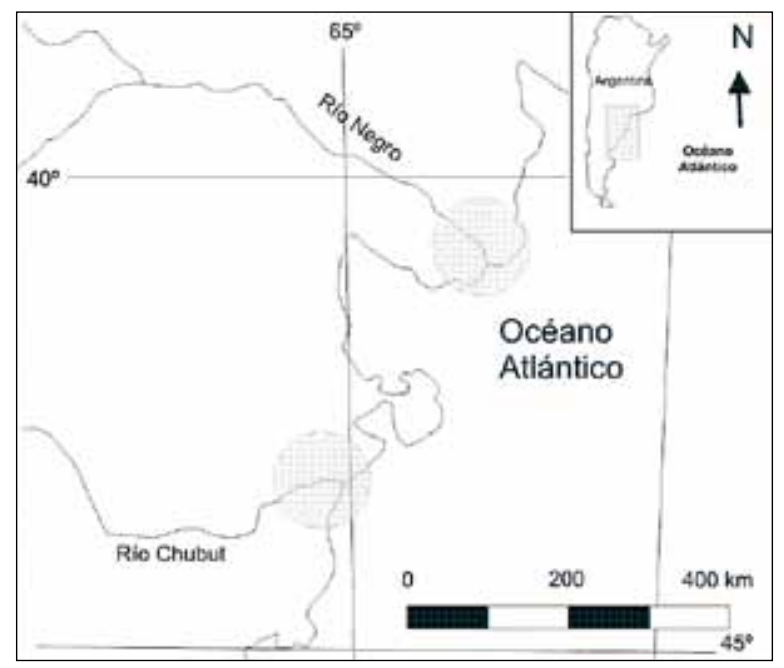

Fig. 1. Procedencia de las muestras analizadas.

Otero y Dahinten 1997/1998). Un tercer grupo mostró deformación tabular erecta planolámbdica (TEPL) ( $n=116)$. Esta modalidad es la de más amplia distribución y frecuencia, la misma fue registrada en el NE de Patagonia, SO de Patagonia, SE de región pampeana y Pampa Seca desde 1.300 años AP, hasta momentos históricos (Barrientos 2001; Barrientos et al. 2005; Bernal et al. 2008; Berón y Baffi 2003; Gómez Otero y Dahinten 1997/1998). Recientemente, Berón y Luna (2008) presentaron un fechado para esta deformación de $1.930 \pm 30$ años AP para el sitio Chillhué (provincia de La Pampa), con lo cual debe considerarse que esta deformación podría poseer un rango temporal más amplio. Un grupo numeroso está conformado por individuos que no presentan deformación artificial, denominados aquí no deformados (ND) ( $\mathrm{n}=177$ ) e indeterminados (I) $(n=10)$. Para los análisis relativos a la distribución temporal de señales de violencia, solo se tuvieron en cuenta a los individuos que presentan deformación artificial del cráneo. Cabe mencionar que se han enviado muestras a fechar mediante el método de AMS. Parte de la muestra está formada por individuos con deformación artificial, cuyos resultados aportarán información a la base de datos general, en cuanto a la correspondencia de modalidades deformatorias en diversos períodos. Asimismo, otra parte de la muestra enviada corresponde a individuos ND que exhiben señales de violencia, los que pueden modificar potencialmente las tendencias temporales observadas. 
Para estos análisis se tuvieron en cuenta únicamente individuos adultos. Se consideró adultos a todos aquellos que al momento de la muerte presentaban la sutura esfeno-basilar cerrada (Buikstra y Ubelaker 1994). Si bien en la actualidad está siendo relevada información relativa a la distribución de señales de violencia en individuos subadultos, por el momento no se han completado los análisis estadísticos correspondientes, por lo cual es un tópico que aún resta ser evaluado.

El registro de las modificaciones óseas se llevó a cabo mediante la sistematización de diferentes variables reunidas en cuatro categorías: 1) fracturas: lineales y estrelladas; 2) depresiones: lineales y subcirculares; 3) marcas de corte: simples, de descarne y tangenciales; 4) perforaciones: con inclusiones y sin inclusiones (para una descripción detallada de las categorías de lesiones y de la metodología de observación y análisis ver Barrientos y Gordón 2004; Gordón 2008; Gordón y Ghidini 2006).

Inferir situaciones de violencia a partir de las huellas relevadas en restos óseos implica cierto grado de incertidumbre, debido al carácter poco específico o ambiguo de muchas de las modificaciones óseas registradas. Con el objetivo de no sobreestimar la cantidad de lesiones atribuidas a situaciones de violencia interpersonal la información relevada fue jerarquizada (Gordón 2008). Un primer paso consistió en la discriminación de alteraciones óseas producto de procesos postdepositacionales. Luego, las lesiones premortem y perimortem fueron tratadas en dos niveles considerando la potencialidad de las lesiones traumáticas asignables a eventos de violencia. Para este trabajo no se tomaron en cuenta los casos con diagnósticos más dudosos (i.e. traumas de carácter multicausal). Es decir, que se contemplaron únicamente aquellos individuos cuyas lesiones traumáticas presentaban bajos niveles de ambigüedad en términos de atribución causal: e.g. individuos con perforaciones con inclusiones -puntas de proyectil incrustadas-, traumas perimortem múltiples asociados, traumas con pátinas, traumas con superficies antiguas, con lascas óseas adheridas a los bordes de fractura, entre otros. De esta forma se esperó incrementar el grado de confianza en los diagnósticos.

El patrón general de violencia interpersonal inferido hasta el momento para el área de estudio puede ser sintetizado de la siguiente forma ( $\mathrm{Ba}$ - rrientos y Gordón 2004; Gordón 2008; Gordón y Ghidini 2006):

1) En ambas zonas (valles inferiores de los ríos Negro y Chubut) se registraron evidencias claras de violencia interpersonal para los momentos más tardíos de la secuencia temporal analizada. Para momentos previos, los traumas registrados resultan ambiguos en términos de atribución causal.

2) En la muestra del valle del río Negro no hay diferencias estadísticamente significativas entre los sexos en cuanto a la frecuencia de señales de violencia interpersonal $(p=0,1451)$, a diferencia de lo que ocurre en el valle del río Chubut, en donde no se registraron individuos femeninos con evidencias claras de violencia.

3) La submuestra del valle del río Negro conformada por individuos masculinos con deformación TEPL exhibe una frecuencia significativamente mayor de señales de violencia que la correspondiente al mismo sexo y tipo de deformación del valle del Chubut $(p=0,0345)$.

4) $\mathrm{Al}$ comparar de manera conjunta ambas muestras, se observó que la frecuencia de lesiones traumáticas es significativamente mayor en la muestra del valle del río Negro $(p=0,027)$.

Los resultados mostraron que los individuos con deformación TEPL presentan todas las categorías de traumas, tanto aquellos del valle del río Negro como los del Chubut. La única excepción es para los individuos con deformación TEPL del valle del río Chubut que no poseen cortes tangenciales. Es de notar la elevada frecuencia de depresiones lineales que exhiben los individuos con deformación TEPL procedentes del valle del río Negro. En algunos casos, estas lesiones están presentes en cráneos pintados con ocre rojo, similares a los recuperados en diversos enterratorios secundarios del noreste de Patagonia y sudeste de la región Pampeana, cuya última aparición en el registro se sitúa hacia 350 años ${ }^{14} \mathrm{C}$ AP (ver Martínez et al. 2006), es decir en momentos iniciales del período colonial. Asimismo, es interesante observar la frecuencia relativamente alta de depresiones subcirculares. También se registró un porcentaje considerable de individuos ND con traumas premortem y/o perimortem (Fig. 2).

Con estos resultados en mente es importante conocer las características generales de la ergología de los grupos cazadores recolectores en general y de aquellos que habitaron el área en particular, como 


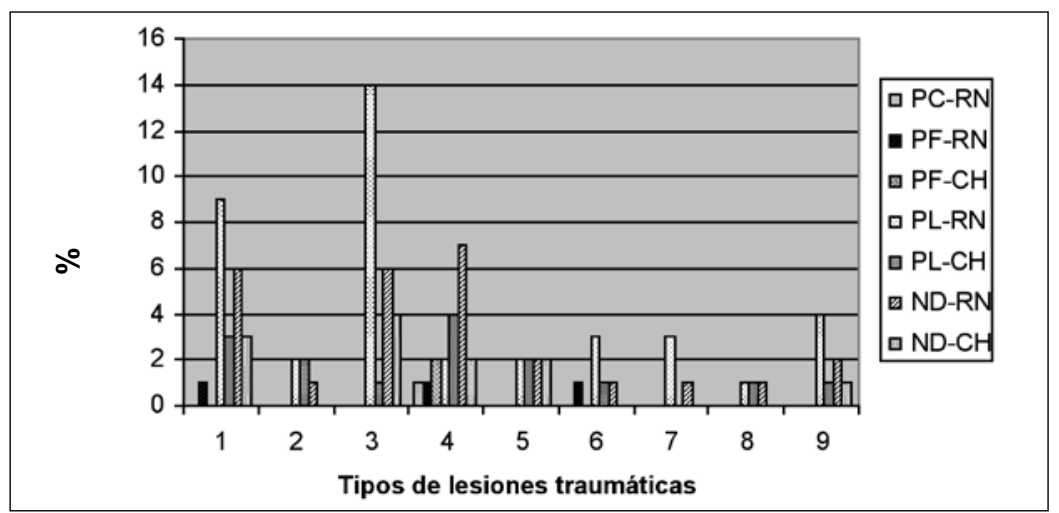

Fig. 2. Distribución temporal y espacial de lesiones traumáticas

(Referencias: PC: pseudo-circular, PF: planofrontal, PL: planolámbica, ND: no deformados; RN: río Negro; $\mathrm{CH}$ : Chubut;

1: Fractura lineal, 2: Fractura estrellada, 3: Depresión lineal, 4: Depresión subcircular, 5: Marcas de corte simple, 6:

Marcas de corte de descarne, 7: Marcas de corte tangencial, 8: Perforación con inclusión, 9: Perforación sin inclusión.

paso previo al análisis experimental, dado que esta información es pasible de ser relacionada con los tipos de daños relevados en el registro bioarqueológico.

\section{ERGOLOGÍA DE CAZADORES RECOLECTORES Y ERGOLOGÍA REGIONAL}

\section{Ergología general de cazadores recolectores}

Para generar inferencias o hipótesis acerca de las relaciones entre clases de efectores (sensu Gifford-González 1991) y clases de traumas óseos, es necesario conocer las características generales del conjunto artefactual de las sociedades de pequeña escala, como marco amplio de contrastación de la ergología de los grupos que habitaron el área.

En este sentido, se siguió el marco propuesto por Nelson (1991) acerca de la organización tecnológica de los grupos cazadores recolectores, dado que este autor hace hincapié en sociedades de pequeña escala y en la tecnología básicamente lítica; dos aspectos fundamentales desde donde analizar la ergología de los grupos humanos que poblaron el área de estudio. Asimismo, se tomaron en cuenta conceptos propuestos por Bleed (1986), Knecht (1997) y Lambert (2002) en relación con esta temática.

En general, es difícil interpretar a las armas en términos de guerra, dado que las utilizadas para ejercer violencia muchas veces también funcionan en actividades de la vida diaria (Lambert 2002; Milner 1999). Sin embargo, Lambert (2002) sugirió que el análisis de las mismas, en conjunto con otras líneas de evidencia, puede aportar al conocimiento del diseño y uso específico de los implementos utilizados para ejercer violencia interpersonal. Como puntualiza la autora, las armas pueden hallarse incrustadas en restos óseos o ser equiparables por forma y tamaño a las lesiones presentes en los esqueletos. Asimismo, propone que la utilización de un arma novedosa y poderosa, como por ejemplo el arco y flecha, puede cambiar las tácticas militares y así la naturaleza y escala de la guerra y sus manifestaciones materiales. Es decir que, a pesar de que las sociedades de pequeña escala pueden no contar con una tecnología especializada para ejercer violencia interpersonal, su ergología es susceptible de ser analizada en términos de armas de guerra en conjunción con otras líneas de evidencia.

En los estudios de organización tecnológica las estrategias más comúnmente reconocidas son la conservación y la expeditividad. La forma de los artefactos y la composición del conjunto son una consecuencia de las diferentes maneras de implementar ambas estrategias. Bleed (1986) propone que es posible optimizar la disponibilidad de un sistema (entendida como la cantidad de tiempo que está disponible para realizar un trabajo) mediante dos estrategias: un sistema puede diseñarse para ser confiable o bien mantenible. Como puntualiza el autor, el mantenimiento o la confiabilidad son alternativas de diseño, no son puntos opuestos de un continum. Los sistemas mantenibles, son los más apropiados para una empresa generalizada que tiene necesidades continuas, impredecibles, pero programadas y generalmente, con bajos costos de fallas. La confiabilidad, por otra parte, es más importante donde el costo de falla es tan alto que el sistema debe trabajar cuando se lo necesita. 
La confiabilidad de un diseño (caracterizada por una redundancia de funciones que pueden ser realizadas con diferentes componentes) puede observarse en los conjuntos a través de la estandarización de la forma y tamaño. También puede ser vista en similares rastros de uso en artefactos formalmente diferentes depositados en un contexto de trabajo similar. Clases o tipos simples pueden tener diferentes rastros de uso y diferentes clases de instrumentos exhibir similares patrones de uso, lo que nos alerta en cuanto a forma y función de los instrumentos, dentro del contexto de pensarlos en términos de armas de guerra. Los instrumentos que presentan diseños mantenibles (hechos para trabajar fácilmente bajo una variedad de circunstancias) pueden ser flexibles, cambiando de forma para satisfacer demandas multifuncionales o versátiles, manteniendo una forma generalizada para satisfacer una variedad de necesidades. La ventaja de los diseños versátiles y flexibles reside en poseer un rango de opciones potencialmente amplio en el uso de los instrumentos. Esta ventaja es importante en situaciones donde el tiempo y lugar específicos de uso de los instrumentos no son totalmente predecibles. Otra ventaja es el potencial para la simplificación de los conjuntos artefactuales ya que los grupos con alta movilidad residencial deben mantener equipos limitados, requiriendo la utilización de algunas clases de instrumentos para múltiples propósitos. Los diseños flexibles requieren formas generalizadas, dado que las especializadas son difíciles de reformatizar. Dentro de las clases de instrumentos que representan el diseño versátil, puede generarse una variedad de rastros de uso debido a la variedad de tareas ejecutadas por los instrumentos de esa clase. Los instrumentos diseñados para ser versátiles deben tener múltiples filos funcionales con evidencias de uso. Los equipos transportables deben ser pequeños, livianos y resistentes a la rotura.

Para sintetizar, se resalta la idea general de que parte del conjunto artefactual de las sociedades de pequeña escala se compone por elementos multipropósito, generalizados e inespecíficos, con bajas inversiones de energía en su manufactura y mantenimiento. Estas características están dadas básicamente por las estrategias de movilidad de estos grupos en relación con su ambiente. No obstante, diversos autores, asimismo, son optimistas frente a las "limitaciones" que ofrece este tipo de registro, alertando acerca de ciertos ítems y planteando análisis y líneas de evidencia complementarias con las cuales sería posible asignar, en cierto grado, la funcionalidad de los implementos: análisis macroscópicos de las herramientas, análisis de microdesgaste de los filos, información procedente de la etnoarqueología, de la etnografía y de la arqueología experimental, entre otras (Ellis 1997; Knecht 1997; Nelson 1991; Odell 1981).

\section{Ergología regional del área de estudio}

En esta sección se presentará una caracterización regional de la tecnología que portaron los grupos humanos que habitaron el noreste de la Patagonia, tanto para momentos previos al período colonial, como así también para los inicios del mismo.

En el último siglo, y con mayor frecuencia en los últimos cuarenta años aproximadamente, diversos equipos de investigación pusieron énfasis en la arqueología del noreste de la Patagonia, resultando de ello un considerable bagaje de información. Dentro del mismo, aquella relacionada con la tecnología que caracterizó a los grupos humanos que habitaron la zona ocupó un lugar de gran importancia.

Las investigaciones arqueológicas que abarcan el área de estudio se desarrollaron principalmente en las márgenes y valles de los ríos Colorado, Negro y Chubut, en el litoral marítimo entre las desembocaduras de los ríos Colorado y Chubut, en las cercanías de la antigua Laguna del Juncal como así también en Bahía San Blas e Isla Gama (Armentano 2004; Bayón et al. 2004; Bórmida 1950, 1964; Cardillo et al. 2007; Cardillo y Scartascini 2007; Favier-Dubois et al. 2006; Gómez Otero 2006; Gómez Otero y Dahinten 1997-98; Gómez Otero et al. 1999; Lehmann Nitsche 1930; Martínez 2004; Martínez y Figuerero Torres 2000; Martínez et al. 2006; Outes 1907; Romer 1996; Torres 1922; Vignati 1931, 1938 entre otros).

Dentro del conjunto artefactual de estos grupos, aquellos que podrían ser potenciales efectores de lesiones del tipo de las depresiones lineales y/o cortes tangenciales son aquellos instrumentos que poseen algún filo o borde delgado. De los instrumentos mencionados para el área aquellos que presentan alguna característica semejante son: filos marginales poco estandarizados con rastros de uso, cuchillos con bordes naturales o retocados, denticulados, filos y puntas naturales con rastros 
complementarios y puntas de proyectil líticas con y sin pedúnculo. Por lo general, se describen puntas triangulares, aunque presentan considerable variabilidad morfológica. Asimismo, se registró la presencia de raspadores, raederas, perforadores y piezas bifaciales. Con respecto a la variabilidad en forma y tamaño de las puntas de proyectil, Gómez Otero señala que este hecho permite inferir el uso de diferentes armas y cambios de diseño a través del tiempo, aunque menciona la posibilidad de que también refleje contactos con poblaciones del norte y sur de la Patagonia. Asimismo, se hallaron deshechos líticos, lascas, núcleos y artefactos de formatización sumaria. Algunos de los elementos sin filo fueron aquellos modificados por uso como percutores, yunques y clastos. Como elementos de golpe contundente se registra la presencia de bolas de piedra con y sin surco. Se señala como parte de un ajuar funerario la presencia de un hacha de bronce (Gómez Otero y Dahinten 1999: 55).

En cuanto a las materias primas, básicamente se utilizaron rodados patagónicos, gravas de origen fluvial y rodados costeros. Los elementos formatizados están confeccionados principalmente con distintos tipos de sílice y basalto y aquellos que se hicieron mediante picado, abrasión y pulido, generalmente están hechos con areniscas. Se registró la presencia de instrumentos en obsidiana, la que podría proceder de los afloramientos de la meseta de Somuncurá (Stern et al. 2000). Se infirió para la zona amplios rangos de movilidad, fundamentalmente para la región más septentrional del área, dado que se hallaron rocas procedentes de Ventania y Tandilia. En las citadas investigaciones, se señala recurrentemente la baja inversión de trabajo para la confección general del conjunto, tanto en el diseño como en la manufactura, y se lo considera informal. Se señaló un escaso desarrollo de la tecnología de hueso y un desarrollo algo mayor de la tecnología de valvas. En el sector más meridional del área se identificó un solo rompecráneos, aunque Gómez Otero no descarta la posibilidad de que armas de materia orgánica (i.e. garrotes) hayan sido usadas para la caza de lobos marinos. Esto podría valer para todos los tipos de armas, es decir que en el contexto de relevamiento del conjunto artefactual general, la ausencia de instrumentos de materia orgánica puede estar dada por factores de conservación diferencial. En general, los fechados de las ocupaciones presentan un rango que oscila entre los 4.000 y los 300 años AP, correspondiendo por lo tanto al Holoceno medio y fundamentalmente al Holoceno tardío.

En general, se identifica el predominio de una estrategia expeditiva dominada por la manufactura de instrumentos de baja inversión de energía y poco estandarizados de confección sumaria, con la existencia de pocos mejor formatizados, como son las puntas de proyectil, las bolas y algunos raspadores. El punto a destacar aquí, es la importante asociación que existe entre el conjunto artefactual y la obtención y procesamiento de diferentes recursos.

En un contexto geográfico más amplio la evidencia arqueológica es coherente con los patrones mencionados en cuanto a uso de materias primas, diversidad de grupos tipológicos e inferencias acerca de los patrones generales de movilidad y uso del espacio por parte de los grupos del noreste de la Patagonia. Este es el caso de los valles medios de los ríos Negro (Prates 2007) y Colorado (Prates et al. 2006), de la región Pampeana (Bayón et al. 2006; Berón 2004, 2006; Berón y Curtoni 1998; Bonomo 2002; Martínez 2002, 2006; Mazzanti 1999; Moirano 1999; Oliva y Barrientos 1988; Politis y Madrid 2001; Valverde 2006 entre otros), de la zona de Cerro Castillo, ubicada al norte de la provincia de Chubut y sur de Río Negro (Belardi 1999; Ratto y Belardi 1999) y de la cuenca del lago Musters (Provincia de Chubut) (Moreno et al.2007).

Por otra parte, la existencia de evidencias de contacto hispano-indígena desde, por lo menos mediados del siglo XVII, hacen necesaria una breve revisión de las característica de la tecnología de ese momento. Si bien este proceso alcanzó su máxima expresión con las Campañas al Desierto, específicamente con la llevada a cabo por el General Julio A. Roca en el año 1879, los primeros contactos habrían comenzado a introducir elementos que modificaron en un corto plazo aspectos de la vida cotidiana de las poblaciones aborígenes. En este sentido, es interesante el uso que hacen Villar y Jiménez (2001) del concepto de Zona Tribal (sensu Ferguson y Whitehead 1992) para el área, dado que en ella se verificaron procesos de transformaciones y modificaciones, a raíz del contacto de sociedades nativas sin estado con sociedades estatales introductoras de nuevos bienes, tecnologías y enfermedades. En este contexto, la introducción de armas blancas y de fuego en el área 
habrían cambiado no solo cuantitativa sino también cualitativamente las manifestaciones de violencia (Lambert 2002). Villar y Jiménez (2001) sugieren que la presencia de sociedades estatales habría conducido a una militarización general, debiéndose entender por tal un incremento de la violencia armada colectiva, cuya conducción, propósitos y medios tecnológicos se adaptaron rápidamente a la nueva situación. Los autores mencionan que para mediados del siglo XVII ciertos grupos de indígenas se mostraban interesados en acceder a los bienes manufacturados, algunos de ellos de utilidad bélica, y ganado que obtenían a cambio de la entrega de personas. Asimismo, reconocen la posesión de armas de acero, espadas anchas, cotas y lanzas para fines de este siglo.

En el bajo curso del río Negro, Moldes de Entraigas (1983) menciona que durante los siglos XVIII y XIX los Tehuelches septentrionales aún utilizaban arcos, flechas, boleadoras, lanzas, cuchillos de pedernal y raspadores, puntas de sílex, carcaj, dardos, hondas, bolas y lazos para cazar. No obstante, puntualiza que los grupos araucanos residentes en la zona usaban lanzas con puntas de hierro, boleadoras, cuchillos o sables y corazas de cuero. Por otra parte, hasta mediados del siglo XIX la corona española invirtió poco en la defensa de los territorios coloniales. El envío de armas desde España era escaso y excepcional, integrándose con piezas de segunda calidad. Hasta la incorporación de las armas reglamentarias para el Ejército, las compras seguían un esquema caótico, dictado por necesidades circunstanciales, motivo por el cual no existe un registro de momentos precisos de la llegada de armas blancas a la región (Suffriti y Albino 1997).

Si bien recién para el siglo XVIII y más aún para el siglo XIX, se cuenta con información abundante y detallada de las armas blancas y de fuego que se hicieron presentes a partir del contacto con la sociedad occidental, se sabe de la existencia para momentos previos de sables, espadas, bayonetas, cuchillos de combate y machetes. Así por ejemplo, cuando el Padre Mascardi realizó su primer viaje en 1670 al Nahuel Huapi, menciona la presencia de un grupo oriundo de la zona de la desembocadura del Negro o del Colorado. Según este autor, estos grupos ...vinieron con mucho lucimiento y gente de a caballo ... con muchos machetones y espadas anchas, frenos, pretales, caballos enjaezados al uso de los españoles y caballos con hierros muy hermosos. (Bechis 1998).

De lo anterior se desprende que los grupos cazadores recolectores que habitaron el área para el Holoceno medio / tardío contaron con una tecnología dominada por un fuerte componente expeditivo en función del modo de subsistencia y patrón de movilidad que los caracterizó, con grados variables pero en general bajos, de estrategias de conservación en el manejo de las materias primas. Puede observarse que dentro del conjunto artefactual, estuvieron presentes elementos multipropósito y generalizados para satisfacer diferentes demandas, acercándose a los diseños flexibles y/o versátiles propuestos por Nelson. Asimismo, se destaca el aspecto transportable de gran parte del equipo, como así también la baja inversión de energía en la manufactura de instrumentos, siendo en general informales y sumarios. Es decir, no existió entre estos grupos una tecnología especializada para ser empleada en contextos de agresión, con lo cual elementos generalizados, ya sea de filo o contundentes, deben haber servido para ejercer violencia interpersonal no organizada. En este punto resulta fundamental y cobra sentido la aplicación de una estrategia de investigación que apunte a explotar diferentes líneas de evidencias para dar cuenta de la potencialidad de ciertos elementos capaces de generar lesiones traumáticas $y$, de esta forma, inferir y dar sentido a las interpretaciones acerca del patrón general de violencia interpersonal inferido para el área. Durante el siglo XVII, el contacto con la sociedad occidental habría modificado sustancialmente las relaciones sociales en general y aquellas asociadas a situaciones de tensión social en particular, tanto entre los grupos aborígenes como así también entre estos con la sociedad occidental. En este sentido, recién para este momento parece haber existido una tecnología especializada para ejercer violencia. Asimismo, su adopción habría sido un proceso relativamente abrupto habiendo generado importantes cambios en las manifestaciones de violencia en diversas escalas (Lambert 2002).

Como parte de la estrategia de investigación aquí propuesta, lo que resta de este trabajo pone fuerte énfasis en el programa experimental actualmente en desarrollo del cual se presentan los primeros resultados. 


\section{ESTUDIOS EXPERIMENTALES EN EL CONTEXTO DE PROBLEMÁTICAS ARQUEOLÓGICAS}

Dado que el objetivo último de la investigación en curso es evaluar posibles consecuencias socioecológicas derivadas de la expansión poblacional ocurrida durante el Holoceno tardío desde el norte de Patagonia hacia el sudeste de la región pampeana (Barrientos y Pérez 2004), es necesario evaluar la frecuencia de señales de violencia que no involucre casos del período de contacto con la sociedad occidental, ya que este proceso ocurrió al menos cuatro siglos más tarde.

Como ya se mencionó, la submuestra de cráneos de individuos más tardíos exhibe deformación TEPL. Hay evidencias de la presencia de esta deformación hasta los primeros momentos de contacto hispano - indígena y es frecuente que la misma se encuentre en individuos que provienen de enterratorios secundarios (e.g. huesos pintados o teñidos con ocre y huesos con marcas de corte de descarne), práctica que tuvo lugar en el área hasta aproximadamente 350 años AP (Barrientos 1997, 2001; Martínez 2004; Martínez et al. 2006). Dada la elevada frecuencia de individuos con depresiones lineales en la muestra más tardía, particularmente en la submuestra del valle inferior del río Negro ( $\mathrm{n}$ $=21 ; 14 \%$ ), se propuso que las mismas podrían haber sido causadas por armas blancas que, como vimos, estuvieron presentes en la zona desde por lo menos mediados del siglo XVII.

Sin embargo, para interpretar marcas sobre restos óseos donde no se cuenta con la presencia de armas en asociación directa se necesita de estudios experimentales con el fin de identificar las características de las marcas que puedan ser diagnósticas de la clase general de arma usada (Lewis 2008).

Dentro del marco de los estudios actualísticos, se formuló un diseño experimental con el objeto de disminuir el grado de ambigüedad en la interpretación de los datos arqueológicos, ya que estos análisis son la única fuente de contrastación de hipótesis que nos permite observar, en este caso, la dinámica entre efectores y huellas y generar criterios diagnósticos para la interpretación de las mismas. Los estudios experimentales tuvieron un amplio desarrollo en arqueología, siendo más abundantes entre aquellos relacionados con temas zooarqueológicos, tafonómicos y tecnológicos (Miller et al. 1986; Odell y Cowan 1986; Rayne-Pickering y Egeland 2006; Shipman y Rose 1984; Walker y Long 1977 entre otros) que entre aquellos bioarqueológicos (Lewis 2008; Smith et al. 2007), siendo útiles en el último caso los aportes procedentes del campo de la antropología forense (Chadwick et al. 1999; Karlsson y Stahling 2000).

\section{Diseño Experimental: materiales y métodos}

Para el desarrollo de la experimentación se utilizaron como proxies de cráneos humanos seis cabezas de cerdos (Sus scrofa domestica) adultos de sexo desconocido. Los mismos conservaron tejidos blandos con excepción de la piel la cual fue previamente retirada. De este modo, la interfase entre el hueso y la superficie de cada cabeza estuvo representada por 3 a $5 \mathrm{~mm}$ de masa muscular y tejido conectivo. La elección de Sus scrofa domestica como análogo experimental se debe al hecho de que esta especie comparte con Homo sapiens un conjunto de características a nivel óseo y cutáneo que la tornan útil en términos comparativos, principalmente en contextos forenses (Dáeid et al. 2008; Humphrey y Hutchinson 2001; Karger et al. 1998; Margulies y Thibault 2000).

Como efectores, fueron utilizadas seis armas blancas originales de filo largo pertenecientes a una colección privada (Colección Pedemonte Méndez), análogas -al menos en sus propiedades fundamentales en cuanto a material, peso y longitud aproximada de hoja- a las que estuvieron en uso en Norpatagonia durante la época colonial temprana. Las mismas fueron:

1- Sable briquet modelo francés 1819 , usado en Argentina por la caballería entre 1825 y 1835 aproximadamente. Esta arma presenta empuñadura de bronce y hoja curva de acero

2- Sable de infantería francés modelo 1822 , usado en Argentina hasta aproximadamente 1860, con hoja de acero. Es un sable pesado y de lomo muy grueso.

3- Primer sable reglamentario del Ejército $\mathrm{Na}$ cional, sable de oficial de Guardia Nacional Modelo Argentino 1870, con hoja y empuñadura de acero. Este sable fue empleado por los oficiales durante la Campaña al Desierto.

4- Sable de caballería Modelo Argentino 1895. Este tipo de sable también fue utilizado en la 
Campaña al Desierto. El mismo tiene empuñadura de cuero o bakelita, guardamano de acero y hoja suavemente curva de acero.

5- Sable de caballería Modelo Argentino 1898. Fue un sable reglamentario de Granadero y Policía Montada, con empuñadura de bakelita y con hoja y guardamano de acero. Su hoja es levemente curva.

6- Sable francés modelo 1890-1900. Con empuñadura de bakelita, guardamano de acero y hoja curva con fuerte lomo. Este sable fue utilizado en Chile, sin embargo fue elegido en este trabajo dado que presenta características muy similares al sable Modelo Alemán 1811 que se usó en Argentina, al cual no se tuvo acceso para el momento de realizar la experimentación.

Cabe aclarar que, si bien estas armas fueron utilizadas en el área durante el siglo XIX, las mismas han sido consideradas como análogos de armas usadas con anterioridad, dado que ciertas características de los individuos analizados (i.e. deformación craneana TEPL, evidencias de prácticas de enterratorios secundarios, fechados radiocarbónicos) los ubican en momentos previos. Es decir, si las depresiones lineales son producto de armas blancas se esperaría estar en presencia del registro de eventos correspondientes a las primeras etapas del contacto entre la sociedad colonial y las sociedades aborígenes del noreste de Patagonia.

Cada arma utilizada se considera representativa de una clase general de armas, aunque se evalúa de una forma amplia la variabilidad de huellas que generan las armas blancas de hoja larga como categoría general, no siendo el objetivo de este trabajo diferenciar las marcas producidas por las diferentes armas usadas. Es decir, lo que aquí interesa es caracterizar la variabilidad de lesiones que las armas blancas de hoja larga pueden dejar en los huesos.

Se registraron variables cuantitativas y cualitativas de las armas utilizadas. Las que describen sus dimensiones son: longitudes (total, de la hoja, del filo y del mango); anchos (máximo y mínimo de la hoja); espesores (máximo y mínimo de la hoja) y el peso. Asimismo, se registró el tipo de función probable (cortante, contundente, punzante, etc.) y la materia prima de la que esta hecho el instrumento. El mismo registro de datos se llevó a cabo con una muestra de armas blancas históricas de la región (n = 40), que forma parte de las colecciones depositadas en el Museo de Armas de la Nación, con el fin de incrementar la base de datos general de armas blancas utilizadas en Argentina.

En cuanto a las cabezas de cerdo, cada una de ellas fue colocada previamente a ser impactada de manera tal que conservara una limitada movilidad relativa al eje vertical, i.e. que no pendiera libremente cuando fuera impactada, ni que quedase completamente fija, ya que ambas situaciones diferirían de la situación de movilidad real producida al golpear a un individuo vivo, obteniéndose consecuentemente patrones de traumas distintos a los que se esperaba replicar. En este sentido, a cada una de las cabezas se le pasó un precinto plástico ajustándose en el plano superior. A su vez, a este precinto le fue sujetada, mediante ganchos plásticos, una soga elástica que pendía desde una viga fija. Por debajo, la cabeza se sostuvo con uno o dos palos de madera a través de los arcos cigomáticos, apoyados sobre una base de hormigón fijada al suelo (Fig. 3).

Cada una de las cabezas fue impactada con un arma por el mismo operario (adulto masculino) seis veces, con el fin de obtener una muestra de 36 marcas susceptible de ser tratada estadísticamente. Posteriormente se llevó a cabo la limpieza de los cráneos mediante hervido con detergente enzimático, dejando que los huesos se secaran a temperatura ambiente durante 4 a 7 días.

Para la descripción de las lesiones, se siguió la terminología específica propuesta por Lewis (2008). El autor identifica al kerf o "piso" de la marca a la indentación linear del final de la profundidad de la hoja. Al tejido óseo situado entre el piso y la superficie externa del hueso lo denomina "pared de la marca de corte". Asimismo, a las áreas sobre la superficie

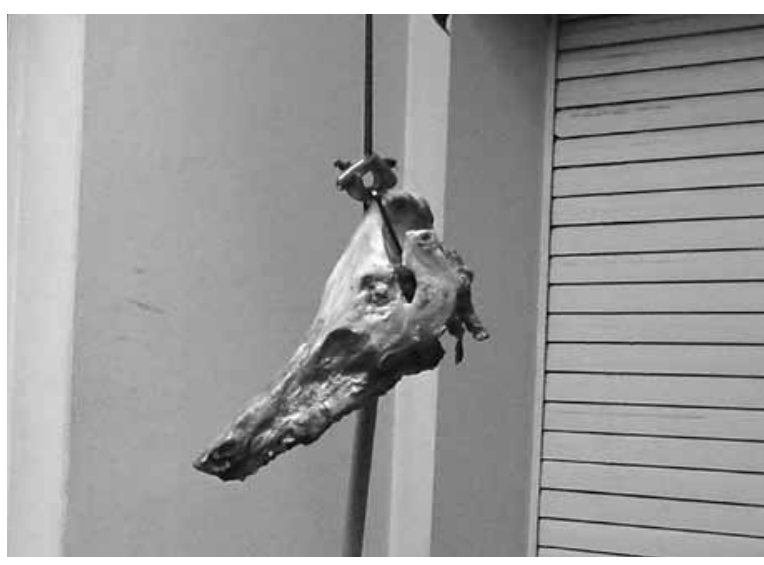

Fig. 3. Ubicación de las cabezas de cerdo para ser impactadas. 


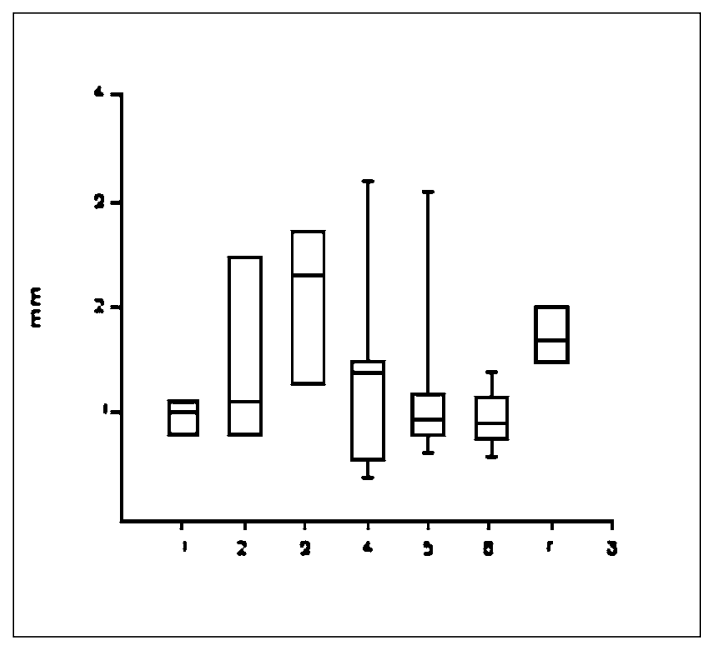

Fig. 4. Anchos de traumas y espesores de filos experimentales: 1-6: dispersión de medianas de anchos de traumas en cada cráneo experimental. 7: dispersión de medianas de filos de las armas experimentales.

externa del hueso, adyacentes a las paredes las llama "lados de la marca de corte".

Se registraron de forma macroscópica las características de los traumas generados de manera análoga al registro de las lesiones de los casos arqueológicos midiéndose la longitud, los anchos mínimo y máximo y la profundidad, cuando fue posible, ya que en ciertos casos la reducida dimensión del trauma no lo permitió. Asimismo, se hizo una descripción cualitativa de la regularidad de los bordes, del piso y de las paredes de la lesión, de la morfología general del surco en sección (semejantes a una $\mathrm{V}$ o una $\mathrm{U}$ ), de la presencia de astillas y/o lascas óseas (Lewis 2008) y la direccionalidad del golpe (en ángulo o perpendicular a la superficie del hueso).

Las marcas fueron examinadas con lupas de pié con luz fría y de mano de bajos aumentos. Las dimensiones se registraron en $\mathrm{mm}$ con calibre vernier de $0,5 \mathrm{~mm}$. Con este calibre fueron tomadas también las dimensiones de las armas, las que fueron además pesadas en gr. con balanza digital.

El tratamiento estadístico de los datos se hizo mediante la aplicación de estadística descriptiva $e$ inferencial. Para comparar las medias de longitud y ancho de los traumas experimentales y arqueológicos se hicieron Pruebas t de Student para muestras independientes y para la comparación de las frecuencias de las diferentes variables cualitativas que definen la forma de las lesiones, se utilizaron pruebas de homogeneidad con el estadístico $\chi 2$. Estas pruebas son

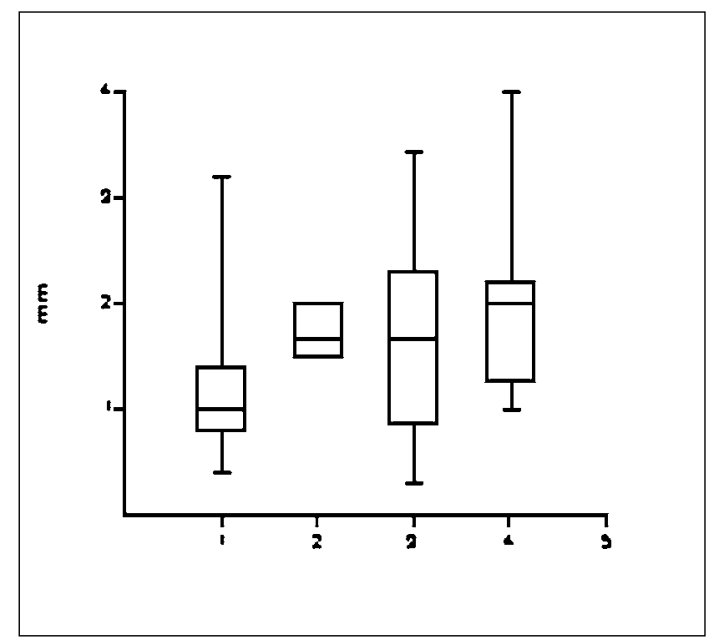

Fig. 5. Anchos de traumas y espesores de filos experimentales y arqueológicos: 1: lesiones experimentales; 2: filos experimentales; 3: lesiones arqueológicas; 4: filos históricos.

equivalentes a las tablas de contingencia excepto que la hipótesis nula indica que las proporciones de las diferentes categorías se distribuyen homogéneamente entre las dos muestras (i.e. marcas experimentales y marcas arqueológicas). En el caso de la variable dirección del golpe se utilizó la corrección de continuidad de Yates para el cálculo de $\chi 2$ (Zar 1999).

Cabe aclarar que, si bien tanto en el caso de las armas como así también en el de las lesiones, se registró el conjunto de variables detallado más arriba, no se presentan los resultados obtenidos para la totalidad del cruce de las mismas, sino únicamente los que fueron considerados diagnósticos y que resumen mayor cantidad de información (i.e. de las armas, aquellas dimensiones relacionadas con la hoja de los instrumentos y de las lesiones las que reflejan la morfología general de la hoja del arma).

\section{Resultados}

Si bien se efectuaron 36 golpes sobre las cabezas de cerdo, se obtuvo una muestra de 31 marcas, ya que 5 no interesaron al material óseo, siendo absorbidos por los tejidos blandos. De esta manera, un primer resultado fue la detección de un porcentaje de subrepresentación de marcas en el registro óseo del 13,86\%.

Las figuras 4 y 5 muestran la distribución de las medianas de los anchos de los traumas y los espesores de los filos. La figura 4, presenta única- 
Tabla 1. Variables cualitativas consideradas en marcas experimentales y arqueológicas. Frecuencias y valores de "p" para el estadístico $\chi 2$.

\begin{tabular}{|c|c|c|c|}
\hline & $\begin{array}{c}\text { Marcas } \\
\text { experimentales } \\
(\mathrm{n}=29)\end{array}$ & $\begin{array}{c}\text { Marcas } \\
\text { arqueológicas } \\
(\mathrm{n}=51)\end{array}$ & $\mathrm{p}$ \\
\hline $\begin{array}{l}\text { REGULARIDAD DE LOS BORDES } \\
\text { Ambos regulares } \\
\text { Ambos irregulares } \\
\text { Uno regular y uno irregular }\end{array}$ & $\begin{array}{c}7 \\
5 \\
17 \\
\end{array}$ & $\begin{array}{c}9 \\
15 \\
27 \\
\end{array}$ & 0,4508 \\
\hline $\begin{array}{l}\text { REGULARIDAD DEL PISO } \\
\text { Regular } \\
\text { Irregular } \\
\text { No se pudo observar } \\
\end{array}$ & $\begin{array}{l}23 \\
3 \\
3 \\
\end{array}$ & $\begin{array}{l}39 \\
6 \\
6 \\
\end{array}$ & 0,6496 \\
\hline $\begin{array}{l}\text { REGULARIDAD DE LAS PAREDES } \\
\text { Ambas regulares } \\
\text { Ambas irregulares } \\
\text { Una regular y una irregular } \\
\end{array}$ & $\begin{array}{c}7 \\
5 \\
17 \\
\end{array}$ & $\begin{array}{c}9 \\
12 \\
30 \\
\end{array}$ & 0,6926 \\
\hline $\begin{array}{l}\text { FORMA DEL SURCO EN SECCIÓN } \\
V \\
U \\
\text { No se pudo observar }\end{array}$ & $\begin{array}{c}17 \\
9 \\
3\end{array}$ & $\begin{array}{l}27 \\
18 \\
6\end{array}$ & 0,8867 \\
\hline $\begin{array}{l}\text { DAÑOS SOBRE LOS LADOS } \\
\text { Sobre ambos } \\
\text { Sin daños } \\
\text { Solo un lado dañado }\end{array}$ & $\begin{array}{c}7 \\
9 \\
13\end{array}$ & $\begin{array}{c}9 \\
9 \\
33\end{array}$ & 0,2086 \\
\hline $\begin{array}{l}\text { PRESENCIA DE LASCAS Y/O ASTILLAS } \\
\text { Lascas } \\
\text { Astillas } \\
\text { Lascas y astillas } \\
\text { Ausencia de ambas }\end{array}$ & $\begin{array}{l}11 \\
4 \\
8 \\
6 \\
\end{array}$ & $\begin{array}{l}21 \\
15 \\
6 \\
9\end{array}$ & 0,1963 \\
\hline $\begin{array}{l}\text { DIRECCION DEL GOLPE } \\
\text { En ángulo } \\
\text { Perpendicular a la superficie }\end{array}$ & $\begin{array}{l}13 \\
16 \\
\end{array}$ & $\begin{array}{l}15 \\
36 \\
\end{array}$ & 0,2519 \\
\hline
\end{tabular}

mente los casos experimentales y la figura 5 exhibe tanto los experimentales como los arqueológicos (en el caso de los filos arqueológicos se refiere a la muestra de armas históricas relevadas en el Museo de Armas de la Nación).

Como se desprende de la observación directa de las figuras, se registró que un rango de variación pequeño de espesores de filos es capaz de generar un rango de dispersión relativamente amplio en el ancho de las lesiones producidas (Fig. 4). Asimismo, se observa que en ambos casos (experimental y arqueológico), los filos son más homogéneos en relación con el rango de dispersión que exhiben los traumas que produjeron. Por otra parte, en ambos casos las medianas de los anchos de las depresiones son levemente menores que las medianas de los espesores de los filos (Fig. 5). No obstante, hay que tener en cuenta que esta asociación directa puede hacerse para el ancho de las lesiones experimentales y el espesor de los filos de las armas que se usaron. La asociación de las mismas variables entre lesiones arqueológicas y espesores de las armas blancas relevadas en el Museo de Armas de la Nación no deja de ser una especulación que se utiliza a modo de comparación con la situación experimental.

Cuando se compararon mediante la Prueba t de Student para muestras independientes el ancho y la longitud de las lesiones experimentales y arqueológicas, se observó que la media de los anchos no se diferenció significativamente $(p=0,068)$. No obstante, las medias de la longitud entre marcas experimentales y arqueológicas difirieron de manera significativa ( $p=<0,0001)$. Es interesante mencionar que las lesiones experimentales que fueron hechas con armas blancas de hoja larga, presentan una longitud promedio $(24,21 \mathrm{~mm})$ que coincide con la observada por Lewis (2008), (22,9 - 24,2 mm). Asimismo, la longitud promedio de las lesiones producidas con cuchillos que este autor presenta (12,7 $\mathrm{mm})$, es muy similar a la longitud promedio de las lesiones arqueológicas obtenidas en nuestro estudio (12,9 mm). Si bien, con esto no se busca 
FLORENCIA GORDÓN

hacer una analogía directa, se presenta este dato para considerar que otros efectores podrían ser los responsables de las lesiones.

En lo que se refiere a las variables cualitativas, la tabla 3 resume la información relevada de la muestra de marcas experimentales y arqueológicas. Considerando un valor de significación correspondiente a 0,05 se observa que ninguna de las variables consideradas muestra diferencias estadísticamente significativas describiendo así similares rasgos morfológicos, y permitiendo por lo tanto aceptar la hipótesis nula planteada, la cual implica que las proporciones de las diferentes categorías se distribuyen homogéneamente entre las dos muestras.

\section{DISCUSIÓN Y CONSIDERACIONES FINALES}

A partir del relevamiento de las lesiones traumáticas en cráneos del noreste de Patagonia en relación con posibles atribuciones causales, se observa que tanto las fracturas (lineales y estrelladas), como las depresiones subcirculares son de carácter multicausal. Es decir que podrían haber sido producidas por una serie de instrumentos y no son específicas de ningún período en particular. Por otra parte, en ausencia de otras evidencias, estas lesiones no indican necesariamente situaciones de violencia, dado que pueden ser provocadas por causas accidentales y de manera no intencional. Las marcas de corte simple y de descarne, en general aparecen asociadas a evidencias de entierros secundarios, así como la presencia de ocre que, como ya se mencionó, fue una práctica común entre las poblaciones del área. Por otra parte, las perforaciones con inclusión no presentan ambigüedades en la interpretación ya que es un indicador directo de situaciones de violencia, en donde pueden ser directamente observados el trauma y su efector. Las perforaciones sin inclusiones, pueden exhibir una morfología bastante particular cuando hubo puntas incrustadas (Smith et al. 2007) o cuando se trata de heridas de bala (Quatrehomme e Iscan 1998 a y b), o bien pueden ser multicausales. Tampoco estas son indicativas de un período en particular, con excepción de las heridas de bala, de todas maneras en la muestra analizada no se identificaron heridas por armas de fuego. Como ocurre con las fracturas y las depresiones subcirculares, en el caso de las perforaciones de carácter multicausal puede resultar ambiguo inferir situaciones de violencia en ausencia de otras evidencias. Un último grupo de traumas representado por depresiones lineales y cortes tangenciales, exhibe un patrón de corte que indica que los mismos fueron causados con efectores de bordes filosos, rectos y en algunos casos muy agudos, como podrían ser armas de hojas metálicas.

Para discutir esta hipótesis, se presentó información de dos líneas de evidencias. Por un lado, se llevó a cabo una revisión bibliográfica acerca de las características generales de la ergología de los grupos cazadores recolectores y de los grupos que habitaron el área, tanto para momentos previos al contacto con la sociedad occidental como así también para momentos tempranos del período colonial. Por otra parte, sobre la base de la hipótesis de que las depresiones lineales y los cortes tangenciales corresponderían, en general, a la acción de armas blancas, se realizó un trabajo experimental con el fin de comparar los resultados derivados con las características de las marcas arqueológicas. En nuestro caso de estudio, es fundamental la identificación de marcas de armas blancas, dado que estas corresponderían a momentos de contacto hispano - indígena $y$, por lo tanto, a momentos posteriores para el cual nos interesa evaluar la dinámica poblacional concordantes con una hipótesis ecológica que se corresponde con el período de la Anomalía Climática Medieval (ca. 1.150 - 600 años calendáricos AP; Stine 1994, 2000).

Diversos autores (Greenfield 1999; Lewis 2008; Walker y Long 1977 entre otros) propusieron una serie de características morfológicas de las lesiones traumáticas generadas tanto con instrumentos de hoja metálica como así también con hojas líticas. Algunas de dichas características se resumen en la tabla 2.

Si se considera las características mencionadas para ambos tipos de efectores y los resultados obtenidos del trabajo experimental aquí presentado, puede inferirse que el grupo de depresiones lineales arqueológicas, el cual presenta un patrón morfológico bastante uniforme, correspondería a las huellas dejadas por una clase de armas de hoja con filo similar a las utilizadas en el caso experimental.

En cuanto al grupo de marcas arqueológicas, vimos que la mayor parte de las mismas se concentra en la submuestra de individuos más tardía, es decir entre aquellos que exhibieron una deformación TEPL. 
Tabla 2. Características generales de las marcas causadas por instrumentos de metal y de piedra (sobre la base de Greenfield 1999; Lewis 2008; Walker y Long 1977).

\begin{tabular}{|c|c|}
\hline Marcas de instrumentos metálicos & Marcas de instrumentos líticos \\
\hline $\begin{array}{l}\text { - Surcos que en sección presentan, generalmente forma de } \mathrm{V} \text {, } \\
\text { exhibiendo una pared suave y uniforme, aunque a veces puede } \\
\text { observarse un perfil en } \mathrm{U} \text { dependiendo de la naturaleza del filo } \\
\text { de la hoja. } \\
\text { - Usadas en ángulo producen } \mathrm{V} \text { asimétricas con una pared } \\
\text { regular y otra irregular. } \\
\text { - Marcas profundas con paredes abruptas: surcos profundos y } \\
\text { angostos o profundos y amplios. } \\
\text { - Paredes que se encuentran en un ápice en el fondo del surco. } \\
\text { - Por lo general, no presentan estriaciones, o si existen, estas } \\
\text { son uniformes. } \\
\text { - Los cortes suelen ser limpios y tajantes. }\end{array}$ & $\begin{array}{l}\text { - Variabilidad morfológica considerable. } \\
\text { - Surcos amplios e irregulares por la sinuosidad de los bordes } \\
\text { cortantes. } \\
\text { - Surcos poco profundos, generalmente las paredes no terminan } \\
\text { en un ápice, exhibiendo un perfil en forma de U. } \\
\text { - Bordes más cóncavos que rectos. } \\
\text { - Los cortes muestran mayor cantidad de deshechos } \\
\text { - Los surcos presentan una serie de estriaciones paralelas como } \\
\text { surcos secundarios, no siendo homogéneas ni en la longitud ni } \\
\text { en el espesor. } \\
\text { - Las marcas siempre son accidentadas en sección con un lado } \\
\text { relativamente abrupto hacia el ápice descendiendo gradualmente } \\
\text { o en una serie de crestas secundarias. }\end{array}$ \\
\hline
\end{tabular}

Las marcas de corte tangencial no fueron evaluadas estadísticamente, dado que sólo pudo replicarse una entre los casos experimentales, con lo cual al menos se pudo observar que las armas blancas son potenciales efectores de este tipo de modificación ósea.

La revisión bibliográfica reveló la presencia de artefactos líticos poco formatizados y de filos más bien romos para el área de estudio. Mientras que para momentos de contacto hispano-indígena se cuenta con registros de la presencia de armas blancas.

A partir de los resultados obtenidos de la comparación de los anchos de las lesiones y de los rasgos que describen su morfología, se propone que las depresiones lineales de los casos arqueológicos fueron causadas por una clase de instrumentos con características similares, al menos en sus propiedades fundamentales en cuanto a material, peso y longitud aproximada de hoja, a las que generaron las lesiones experimentales. No obstante, las longitudes de ambas muestras de marcas resultó ser estadísticamente diferente, coincidiendo con la media propuesta para cuchillos metálicos por Lewis (2008), con lo cual es posible que otro efector metálico de hoja corta las haya causado. Por otra parte, ninguno de los rasgos cualitativos que definen la morfología de los traumas muestra diferencias estadísticamente significativas entre ambos grupos de marcas. En las figuras 6 a - c y 7 a - c se muestran marcas de origen arqueológico y experimental en donde puede observarse la similitud morfológica que exhiben.

En general, los rasgos mencionados llevan a suponer que este patrón de lesiones traumáticas fue característico del período de contacto hispanoindígena, particularmente del representado por los primeros momentos del período colonial, ya que este tipo de lesión por posible arma blanca aparece, generalmente, en individuos cuyas características morfológicas y contextuales permiten ubicarlos en momentos previos a 350 años AP.

Si bien aún resta complementar este estudio con resultados procedentes de otras líneas (i.e. análisis de las huellas mediante la aplicación de MEB, fechados radiocarbónicos y análisis de filos líticos, básicamente) ciertos puntos merecen ser destacados. En principio, el valor que poseen los estudios actualísticos como fuentes de hipótesis en el contexto de
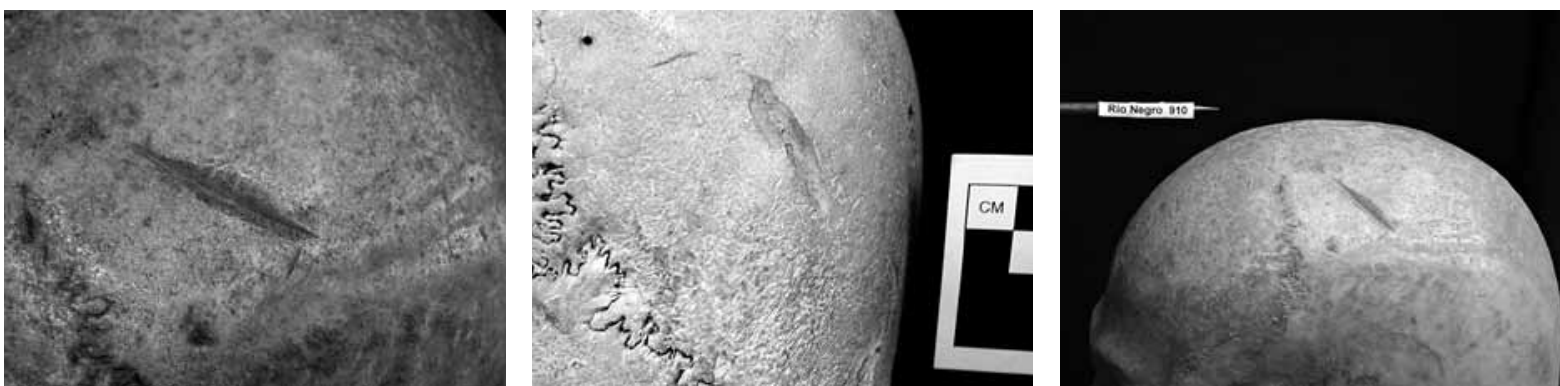

Figs. 6 a - c. Depresiones lineales arqueológicas. 

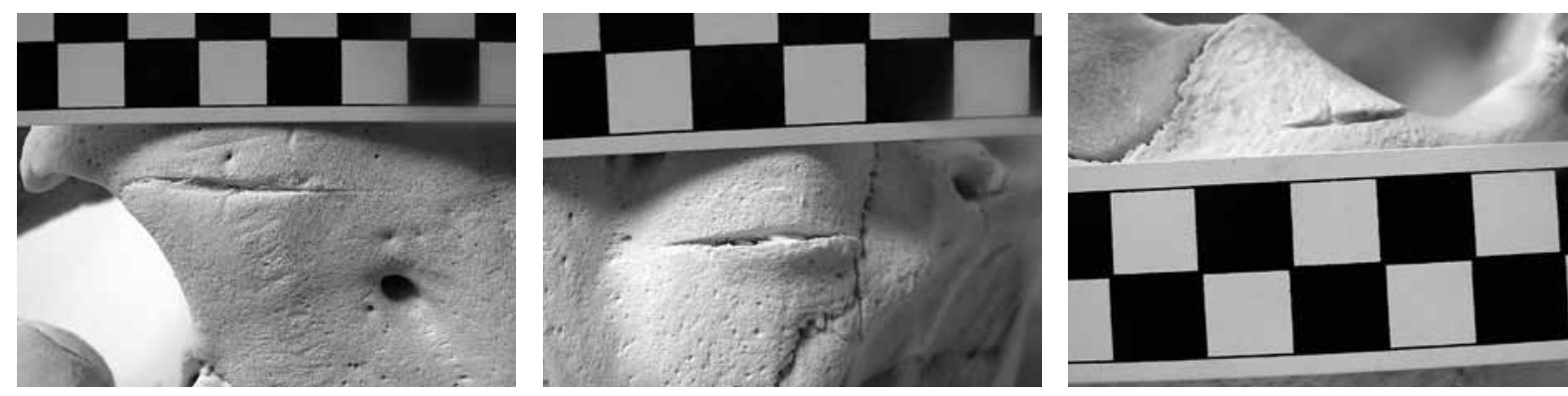

Figs. 7 a - c. Depresiones lineales experimentales.

problemáticas arqueológicas. En este sentido, si bien los resultados aquí presentados son un primer paso, vimos que esta metodología contribuyó a refinar las interpretaciones de parte de la muestra analizada, representando el 5,5\%(21/377) de la muestra total de individuos y el $55,26 \%$ (21/38) de los casos con lesiones traumáticas. Asimismo permitió identificar un nivel de subrepresentación en la expresión de traumas óseos asociados a situaciones de violencia, que no puede dejarse de lado.

El procedimiento analítico desarrollado en este trabajo, basado en una combinación de diversas líneas de evidencia (registro y descripción cualitativa y cuantitativa de marcas óseas de origen arqueológico, revisión bibliográfica del conjunto artefactual de los grupos humanos que habitaron el noreste de la Patagonia, y desarrollo de un programa experimental y posterior relevamiento de marcas) mostró ser una herramienta útil para el proceso de generación de criterios diagnósticos de lesiones traumáticas como así también en lo que se refiere a la interpretación de las mismas, es decir a sus posibles correlatos causales.

Mediante este trabajo se espera haber hecho una contribución en dos sentidos: por un lado, en un sentido metodológico, ya que por medio de la aplicación del programa experimental se vio que la hipótesis formulada pudo ser contrastada mediante la observación directa de la interacción entre efectores y trazas. Dentro de la esfera metodológica, la estrategia de implementar el uso de más de una línea de evidencias para dar sentido a una ergología generalizada en función de la interpretación de las lesiones traumáticas, también mostró ser útil aportando a la robustez de tales interpretaciones. Por otro lado, se espera haber contribuido al esquema general de dinámica poblacional para el noreste de Patagonia durante el Holoceno tardío.
Por último, se pretende haber avanzado en lo que respecta a la interpretación cronológica general de ciertas lesiones traumáticas que se observan en el registro bioarqueológico, ya que ciertas características de tales lesiones se corresponderían con rasgos de armas blancas y que no hay registro de las mismas en el área hasta momentos de contacto hispano-indígena.

\section{AGRADECIMIENTOS}

A Diego Rindel, Juan Bautista Belardi y Gustavo Barrientos por la lectura atenta del manuscrito y sus (siempre) enriquecedores comentarios. Al jefe de la División Antropología del Museo de La Plata, Dr. Héctor M. Pucciarelli, por permitirme el acceso a las colecciones a su cargo. Asimismo, el director del Museo de Armas de la Nación, Cnel. Arístides R. Bonino y las Lic. María Marta Bassús y María Alejandra González Cevallo me cedieron con total generosidad el acceso a las colecciones de armas allí depositadas. A Noemí Maziriz y a los Dres. Carlos Vicari, Horacio Peláez y Juan Boto por facilitarme el material experimental. Al Dr. Luis Bosio y al Servicio de Antropología Forense de la morgue judicial, quienes brindaron su espacio y materiales para la limpieza de los restos óseos experimentales. El Dr. Jorge Pedemonte Méndez y familia, no solo pusieron a mi disposición su colección de armas sino también su hogar y su tiempo para el desarrollo del trabajo experimental. Ariel Frank corrigió el abstract de este trabajo. Luciano Prates, Iván Pérez y Fernando Archuby compartieron conmigo sus conocimientos facilitándome generosamente bibliografía de diversos temas. Al comité editorial y a los evaluadores anónimos por sus pertinentes comentarios. Este trabajo se enmarca dentro del proyecto de tesis doctoral financiado por CONICET. 


\section{BIBLIOGRAFÍA CITADA}

ARMENTANO, G. 2004. Organización de la tecnología lítica en el Valle Inferior del Río Colorado (Partidos de Patagones y Villarino, Pcia. de Buenos Aires). Tesis de licenciatura inédita. Olavarría, Departamento de Arqueología, Facultad de Ciencias Sociales Universidad Nacional del Centro de la Provincia de Buenos Aires. MS.

BARRIENTOS, G. 1997. Nutrición y Dieta de las Poblaciones Aborígenes Prehispánicas del Sudeste de la Región Pampeana. Tesis de Doctorado, Facultad de Ciencias Naturales y Museo, Universidad Nacional de La Plata. MS

BARRIENTOS, G. 2001. Una aproximación bioarqueológica al estudio del poblamiento prehispánico tardío del sudeste de la region Pampeana. Intersecciones en Antropología 2: 3-18.

BARRIENTOS, G. y F. GORDÓN. 2004. Explorando la relación entre nucleamiento poblacional y violencia interpersonal durante el Holoceno tardío en el noreste de Patagonia (República Argentina). Magallania 32:53-69.

BARRIENTOS, G., S. PÉREZ, V. BERNAL, P. GONZÁLEZ, M. BÉGUELIN y M. DEL PAPA. 2005. Changing views about the local evolution of human populations in the Argentine Pampas during the Holocene. En: Proceedings of the 5th Annual Conference of the British Association for Biological Anthropology and Osteoarchaeology, editado por S. Zakrzewski y M. Clegg, pp. 93-104. British Archaeological Reports 1383, Oxford.

BARRIENTOS, G. e I. PÉREZ. 2004. La expansión y dispersión de poblaciones del norte de Patagonia durante el Holoceno tardío: evidencia arqueológica y modelo explicativo. En: Contra Viento y Marea. Arqueología de la Patagonia, editado por T. Civalero, P. Fernández y G. Guraieb, pp.179-195, Buenos Aires.

BASSÚS, M. M. 2008. Historia y Evolución de las Armas. Volumen I. Circulo Militar. Museo de Armas de La Nación, M.S.

BAYÓN, C., G. MARTÍNEZ, G. ARMENTANO, C. SCABUZZO. 2004. Arqueología del Valle inferior del Río Colorado. Sitio La Primavera. Intersecciones en Antropología 5:39-55.

BAYÓN, C., N. FLEGENHEIMER y A. PUPIO. 2006. Planes sociales en el abastecimiento y traslado de roca en la Pampa bonaerense en el Holoceno temprano y tardío Relaciones de la Sociedad Argentina de Antropología XXXI:19-45

BECHIS, M. 1998. Prólogo. En: Identidades Impuestas. Tehuelches, Aucas y Pampas en el Norte de la Patagonia, de L. R. Nacuzzi, pp. 9-14. Sociedad Argentina de Antropología, Buenos Aires.
BELARDI, J. B. 1999. Cuevas, aleros, distribuciones y poblamiento. En: Arqueología. Sólo Patagonia. Ponencias de las segundas jornadas de Arqueología de la Patagonia. J. Gómez Otero (ed.). Publicación del Centro Nacional Patagónico Consejo Nacional de Investigaciones Científicas y Técnicas. Puerto Madryn.

BERNAL, V., P. N. GONZÁLEZ, S. I. PÉREZ y H. M. PUCCIARELLI. 2008. Entierros humanos del noreste de Patagonia: nuevos fechados radiocarbónicos. Magallania 36 (2): 125-134.

BERÓN, M. 2004. Dinámica poblacional y estrategias de subsistencia de poblaciones prehispánicas de la cuenca Atuel-Salado-Chadileuvú-Curacó, Provincia de La Pampa. Tesis doctoral inédita. Facultad de Filosofía y Letras, UBA.

BERÓN, M. 2006. Base regional de recursos minerales en el occidente pampeano. Procedencia y estrategias de aprovisionamiento. Relaciones de la Sociedad Argentina de Antropología XXXI:47-88.

BERÓN, M. e I. BAFFI. 2003. Procesos de cambio cultural en los cazadores-recolectores de la provincia de La Pampa, Argentina. Intersecciones en Antropología 4: 29-43.

BERÓN, M. y R. CURTONI. 1998. Investigaciones arqueológicas en la Subregión Pampa Seca, Cuenca del río Curacó, Pcia. de La Pampa. Intersecciones en Antropología 2:5-30.

BERÓN, M. y L. LUNA. 2008. Distribución espacial y cronológica de la deformación craneana tabular erecta en Pampa y Norpatagonia. Libro de Resúmenes VII Jornadas de Arqueología de la Patagonia, pp. 45. Ushuaia.

BLEED, P. 1986. The optimal desing of hunting weapons: maintainability or reliability American Antiquity 51 (4):737-747.

BONOMO, M. 2002. Distribución espacial y tecnología en el litoral marítimo bonaerense. En: Mazzanti, D., M. Berón y F. Oliva (eds.) En: Del Mar a los Salitrales. 10000 años de historia pampeana en el umbral del tercer milenio, pp. 185-204. Universidad Nacional de Mar del Plata.

BÓRMIDA, M. 1950. Cementerios indígenas prehispánicos en la zona de la laguna del Juncal. Anales del Museo Nahuel Huapi 2: 101-108.

BÓRMIDA, M. 1964. Arqueología de la costa Norpatagónica. Trabajos de Prehistoria XIV. Madrid.

BUIKSTRA, J. E. y D. H. UBELAKER. 1994. Standards for Data Collection from Human Skeletal Remains. Arkansas Archeological Survey Research Series N44, Arkansas.

CARDILLO, M., C. FAVIER-DUBOIS, F. SCARTASCINI y L. LÍPARI. 2007. Una aproximación a la diversidad en la tecnología lítica de la costa norte del Golfo San Matías, Río Negro, Argentina. Resúmenes del XVI Congreso 
Nacional de Arqueología Argentina, Tomo III pp. 323328, San Salvador de Jujuy.

CARDILLO, M. y F. SCARTASCINI. 2007. Tendencias observadas en las estrategias de explotación de recursos líticos en el Golfo San Matías. Provincia de Río Negro. Argentina. En: Arqueología de Fuego-Patagonia. Levantando piedras, desenterrando huesos... y Develando Arcanos. Pp. 117127. F. Morello, M. Martinic, A. Prieto y G. Bahamonde (eds.).Ediciones CEQUA. Punta Arenas, Chile.

CHADWICK, E. K. J., A. C. NICOL, J. V. LANE, T. G. F., GRAY. 1999. Biomechanics of knife stab attacks Forensic Science International 105:35-44

DAÉID, N. N., M. CASSIDY, S. MCHUGH. 2008. An investigation into the correlation of knife damage in clothing and the lengths of skin wounds Forensic Science International 179:107-110

DEMBO, A. e J. IMBELLONI. 1938. Deformaciones Intencionales del Cuerpo Humano de Carácter Étnico, J. Anesi, Buenos Aires.

EUGENIO, E. O. y V. ALDAZABAL. 2004. Los cazadores recolectores del litoral marítimo del área de Bahía de San Blas, provincia de Buenos Aires En: Contra Viento y Marea. Arqueología de la Patagonia, editado por T. Civalero, P. Fernández y G. Guraieb, pp.687-700, Buenos Aires.

ELLIS, C. J. 1997. Factors influencing the use of stone projectile tips: an ethnographic perspective. En: Projectile Technology. Knecht (Ed.), pp. 37-74. Plenum Press, New York and London.

FAVIER-DUBOIS C. M., BORELLA F., MANZI L., CARDILLO M., LANZELLOTTI S., SCARTASCINI F., MARIANO C., y BORGES VAZ E. 2006. Aproximación regional al registro arqueológico de la costa rionegrina. En: Arqueología de la Costa Patagónica. Perspectivas para la Conservación. Editado por I. Cruz y M. S. Caracotche, Cap. 3, pp. 50-68. Universidad Nacional de la Patagonia Austral, Río Gallegos.

FERGUSON, R. B. y N. L. WHITEHEAD. 1992. The violent edge of empire. En: War in the Tribal Zone: Expanding State and Indigenous Warfare, editado por R. B. Ferguson y N. L. Whitehead, pp. 1-30. School of American Research Press

GAT, A. 1999. The pattern of fighting in simple, small-scale, prestate societies. Journal of Anthropological Research 55:563-583.

GAT, A. 2000. The human motivational complex: Evolutionary theory and the causes of hunter-gatherer fighting. Anthropological Quarterly 73: 20-34.

GIFFORD-GONZÁLEZ, D. P. 1991. Bones are not enough: analogues, knowledge, and interpretive strategies in zooarchaeology. Journal of Anthropological Archaeology 10:215-254.

GÓMEZ-OTERO, J. 2006. Dieta, Uso del Espacio y Evolución de las Poblaciones Cazadoras-Recolectoras de la Costa Centro-Septentrional de Patagonia durante el Holoceno Medio y Tardío. Tesis doctoral. Facultad de Filosofía y Letras, Universidad de Buenos Aires. MS

GÓMEZ OTERO, J. y S. DAHINTEN. 1997/1998. Costumbres funerarias y esqueletos humanos: variabilidad y poblamiento en la costa nordeste de la provincia de Chubut (Patagonia Argentina). Relaciones de la Sociedad Argentina de Antropología (N.S.) 22/23: 101-124.

GÓMEZ OTERO, J. y S. DAHINTEN. 1999. Evidencias de contactos interétnicos en el siglo XVI en Patagonia: informe preliminar sobre el sitio enterratorio Rawson (Chubut) Actas del XII Congreso Nacional de Arqueología Argentina Tomo III: 44-53. Editor Cristian Diez Marín, Universidad Nacional de La Plata.

GÓMEZ OTERO J., J. B. BELARDI, A. SÚNICO y R. TAYLOR. 1999. Arqueología de cazadores-recolectores en península Valdés (costa central de Patagonia): primeros resultados. En: Soplando en el Viento. Actas de las III Jornadas de Arqueología de la Patagonia. Instituto Nacional de Antropología y Pensamiento Latinoamericano y Universidad Nacional del Comahue, Facultad de Humanidades. Neuquén-Buenos Aires

GORDÓN, F. 2007. El estudio de la violencia en sociedades de pequeña escala: bases conceptuales para la construcción de modelos aplicables a casos arqueológicos. Libro de las VII Jornadas de Jóvenes Investigadores en Ciencias Antropológicas, Buenos Aires, en prensa.

GORDÓN, F. 2008. Tafonomía humana y lesiones traumáticas en colecciones de museos. Evaluación de cráneos del noreste de Patagonia. Intersecciones en Antropología. En prensa.

GORDÓN, F. y G. GHIDINI. 2006. Análisis bioarqueológico de la violencia interpersonal. El valle inferior del río Negro (República Argentina) durante el Holoceno tardío. Revista Werken 9: 27-45.

GREENFIELD, H. J. 1999. The origins of metallurgy: distinguishing stone from metal cut-marks on bones from archaeological sites Journal of Archaeological Science 26:797-808

HUMPHREY, J. H. y D. L. HUTCHINSON. 2001. Macroscopic characteristics of hacking trauma. Journal of Forensic Science 46: 228-233.

IMBELLONI, J. 1924-25. Deformaciones intencionales del cráneos en Sud América. Revista del Museo de La Plata 28: 329-407. 
KARGER, B., H. SUDHUES, B. P. KNEUBUEHL, B. BRINKMANN. 1998. Experimental arrow wounds: ballistics and traumatology Journal of Trauma-Injury Infection \& Critical Care 45 (3):495-501

KARLSSON, T. y S. STAHLING. 2000. Experimental blowgun injuries, ballistic aspects of modern blowgun Forensic Science International 112:59-64.

KNECHT, H. 1997. The history and development of projectile technology research. En: Projectile Technology. Knecht (Ed.), pp.3-35. Plenum Press, New York and London.

LAMBERT, P. 2002. The Archaeology of War: A North American Perspective. Journal of Archaeological Research, 10 (3): 207-241.

LEHMANN-NITSCHE, R. 1930. Un cráneo Patagón con pinturas geométricas en rojo y negro procedente de San Blas (costa Atlántica). Revista del Museo de La Plata Tomo XXXII: 293- 297.

LEWIS, J. E. 2008. Identifying sword marks on bone: criteria for distinguishing between cut mark made by different classes of bladed weapons. Journal of Archaeological Science. 35 (7): 2001-2008

MARGULIES, S.S. y K. L. THIBAULT. 2000. Infant skull and suture properties: measurements and implications for mechanisms of pediatric brain injury. Journal of Biomechanical Engineering 22 (4): 364-371

MARTÍNEZ, G. 2002. Organización y cambio en las estrategias tecnológicas: un caso arqueológico e implicaciones comportamentales para la evolución de las sociedades cazadoras-recolectoras pampeanas. En: Perspectivas Integradoras entre Arqueología y Evolución. Editado por: G. Martínez y J. L. Lanata. INCUAPA, Olavarría.

MARTÍNEZ, G. 2004. Resultados preliminares de las investigaciones arqueológicas realizadas en el curso inferior del río Colorado (Partidos de Villarino y Patagones, Pcia. de Buenos Aires). En: Aproximaciones Arqueológicas Pampeanas: Teorías, Métodos y Casos de Aplicación Contemporáneos G. Martínez, M. Gutierrez, R. Curtoni, M. Berón y P. Madrid (eds.) FACSO-UNCPBA, Olavarría, pp.275-292.

MARTíNEZ, G. 2006. Arqueología del curso medio del río Quequén Grande: estado actual y aportes a la arqueología de la región pampeana Relaciones de la Sociedad Argentina de Antropología XXXI:249-275

MARTÍNEZ, G. y M. FIGUERERO TORRES. 2000. Sitio arqueológico La Petrona (Partido de Villarino, Pcia. Bs. As.): análisis de la modalidad de entierro en el área sur pampeana Relaciones de la Sociedad Argentina de Antropología XXV:227-248.
MARTÍNEZ G., P. BAYALA, G. FLENSBORG y R. LÓPEZ. 2006. Análisis preliminar de los entierros humanos del sitio Paso Alsina 1 (Pdo. de Patagones Pcia. de Buenos Aires) Intersecciones en Antropología 7: 95-108.

MARTÍNEZ G., A. F. ZANGRANDO y L. PRATES. 2009. Isotopic ecology and human palaeodiets in the lower basin of the Colorado river, Buenos Aires Province, Argentina. International Journal of Osteoarchaeology 19: 281-296.

MAZZANTI, D. 1999. Ocupaciones humanas tempranas en Sierra La Vigilancia y Laguna La Brava, Tandilia Oriental (Pcia. Bs. As.) Actas del XII Congreso Nacional de Arqueología Argentina 3:145-148.

MILLER R., E. McEWEN, C. BERGMAN. 1986. Experimental approaches to ancient near eastern archery World Archaeology Weaponry and warfare 18 (2): 178-195.

MILNER, G. R. 1999. Warfare in prehistoric and early historic eastern north America. Journal of Archaeological Research 7 (2): 105-151.

MOIRANO, J. 1999. Aprovisionamiento de recursos líticos y variabilidad artefactual en el sur de la sub-región Pampa Húmeda: la revisión de las colecciones particulares Relaciones de la Sociedad Argentina de Antropología XXIV: 237-255

MOLDES DE ENTRAIGAS, B. 1983. Arqueología y etnohistoria del bajo curso del río Negro. Presencia Hispánica en la Arqueología Argentina Vol. 2. Editado por E. S. Morresi y R. Gutiérrez, pp. 877-893. Museo Regional de Antropología "J. A. Martinet" - Instituto de Historia, Facultad de Humanidades, UNNE, Resistencia.

MORENO, E., VIDELA, B., H. PÉREZ RUÍZ, L. ASENCIO, V. LEONFORT. 2007. Búsqueda de indicadores de diversificación económica prehistórica en la cuenca del Lago Musters (Chubut, Argentina). En: Arqueología de Fuego-Patagonia. Levantando piedras, desenterrando huesos... y Develando Arcanos. Pp. 23-32 F. Morello, M. Martinic, A. Prieto y G. Bahamonde (eds.).Ediciones CEQUA. Punta Arenas, Chile.

NELSON, M. 1991. The study of technological organization. Archaeological Method and Theory 3:57-100.

ODELL, G. H. 1981. The morphological express at function junction: searching for meaning in lithic tool types. Journal of Anthropological Research 37 (4): 319-342

ODELL, G. H. y F. COWAN. 1986. Experiments with spears and arrows on animals targets Journal of Field Archaeology 13(2): 195-212.

OLIVA, F. y G. BARRIENTOS. 1988. Laguna de Puán: un potencial sitio de aprovisionamiento de materia prima lítica. Libro de resúmenes del IX Congreso Nacional de Arqueología Argentina, pp. 46-47, Buenos Aires. 
OUTES, F. 1907. Arqueología de San Blas (provincia de Buenos Aires) Anales del Museo de Nacional de Buenos Aires 16: 249-273.

PÉREZ, S. I. 2006. El Poblamiento Holocénico del Sudeste de la Región Pampeana: Un Estudio de Morfometría Geométrica Craneofacial. Tesis doctoral inédita. Facultad de Ciencias Naturales y Museo, Universidad Nacional de La Plata. MS

POLITIS, G. y P. MADRID. 2001. Arqueología pampeana: estado actual y perspectivas. En: Historia Argentina Prehistórica pp. 737-814 E. Berberian y A. Nielsen (eds.), Ed. Brujas, Córdoba.

PRATES, L. 2007. Arqueología del Valle Medio del Río Negro (Provincia de Río Negro). Tesis doctoral. Facultad de Ciencias Naturales y Museo, Universidad Nacional de La Plata.

PRATES, L., G. MARTÍNEZ, y C. SCABUZZO. 2006. Evidencias arqueológicas del Holoceno tardío final en el curso medio del río Colorado (Provincia de Río Negro): sitio Don Aldo 1 Cazadores Recolectores del Cono Sur. Revista de Arqueología 1:163-177

QUATREHOMME, G. e M. Y. ISCAN. 1998. a Analysis of beveling in gunshot entrance wounds Forensic Science International 93: 45-60.

QUATREHOMME, G. e M. Y. ISCAN. 1998. b Gunshot wounds to the skull: comparison of entries and exits Forensic Science International 94: 141-146.

RATTO, N. y J. B. BELARDI. 1999. Selección y uso de materias primas líticas en la región de Cerro Castillo (Provincias de Chubut y Río Negro). En: Arqueología. Sólo Patagonia. J. Gómez Otero (ed.) Ponencias de las segundas jornadas de Arqueología de la Patagonia.

RAYNE PICKERING, T. y C. P. EGELAND. 2006. Experimental patterns of hammerstone percussion damage on bones: implications for inferences of carcass processing by humans. Journal of Archaeological Science 33:459-469.

ROMER, X. 1996. Estrategias de movilidad en el sector norte de la costa de Río Negro. Tesis de licenciatura. Facultad de Filosofía y Letras, UBA. MS.

SHIPMAN, P y J. J. ROSE. 1984. Cutmark mimics on modern and fossil bovid bones Current Anthropology 25 (1):116-117.

SILBERBAUER, G. 1993. Ethics in small scale societies En: A Companion to Ethics (editado por P. Singer) Wiley Blackwell.
SMITH, E. A. 2003. Competition and warfare. ANTH 457: Ecological Anthropology Lecture Notes. http://courses. washington.edu/anth457/competit.htm. 24/02/2004.

SMITH M. J., M. B. BRICKLEY, S. y L LEACH. 2007. Experimental evidence for lithic projectile injuries: improving identification of an under-recognised phenomenon Journal of Archaeological Science 34: 540-553.

STERN, C., J. GÓMEZ OTERO y J. B. BELARDI. 2000. Características químicas, fuentes potenciales y distribución de diferentes tipos de obsidianas en la costa e interior del centro-norte de la provincia del Chubut, Argentina. Magallania 28: 275-290.

STINE, S. 1994. Extreme and persistent drought in California and Patagonia during mediaeval time. Nature 369:546-549.

STINE, S. 2000. On the Medieval climatic anomaly. Current Anthropology 41:627-628.

SUFFRITI, M. A. y O. C. ALBINO. 1997. Bayonetas de la República Argentina Edición de los Autores, Bueno Aires

TORRES L. M. 1922. Arqueología de la Península San Blas (provincia de Buenos Aires). Revista del Museo de la Plata XXVI: 473-532.

UBELAKER, D. H. 1991. Perimortem and postmortem modification of human bone. Lessons from forensic anthropology. Anthropologie XXIX/3

VALVERDE, F. 2006. Estrategias de conservación y economía de la materia prima lítica en contextos tempranos de las sierras de Tandilia oriental Cazadores Recolectores del Cono Sur. Revista de Arqueología 1: 179-187

VIGNATI, M. A. 1931. Investigaciones antropológicas en el litoral marítimo sudatlántico bonaerense. Notas Preliminares del Museo de La Plata 1:19-31

VIGANTI, M. A. 1938. Cráneos pintados del cementerio indígena de San Blas. Revista del Museo de La Plata (N.S.) 1(4): 35-52.

VILLAR, D. y J. F. JIMÉNEZ. 2001. "Para servirse de ellos": cautiverio, ventas a la usanza del pays y rescate de indios en las Pampas y Araucanía (siglos XVII-XIX) Relaciones de la Sociedad Argentina de Antropología XXVI: 31-55.

WALKER, P. L. y J. C. LONG. 1977. An experimental study of the morphological characteristics of tool marks. American Antiquity 32 (4):605-616.

ZAR, J. H. 1999. Biostatistical Analysis Prentice Hall $4^{\text {th }}$ edition, Illinois. 